\title{
ESTUDIOS
}

\section{Defender al pobre y proteger la naturaleza}

\section{Patxi Álvarez de los Mozos S. I.'}

Resumen: Laudato si' no es una "encíclica verde", en un sentido reductivamente ecológico. Es una alabanza a la vida y una llamada a cuidar de la casa común. En este artículo se dilucidan algunos modos en que la degradación del medioambiente impacta sobre los más pobres. A continuación se muestran las últimas causas que producen esta agresión simultánea sobre la vida, una cuestión a la que la encíclica dedica amplia atención. La respuesta ofrecida por el documento a esta doble crisis consiste en la ecología integral, desarrollando sus contenidos. El trabajo finaliza con una conclusión que apunta a algunos nuevos paradigmas que aparecen esbozados en la propia LS y que pueden abrir vías de solución a la crisis socio-ambiental que afrontamos.

Palabras clave: ecología integral, opción por los pobres, vulnerabilidad de la creación, crisis socio-ambiental, justicia socio-ambiental, desarrollo humano sostenible.

\section{Defend the poor and protect the nature}

Abstract: Laudato si ' is not a "green encyclical" in a narrow ecological sense. This paper shows a sign of praise for life and a call to take care of our common home. This paper sheds light on several cases where environmental degradation impacts on the poorest. After that, the root causes that produce this simultaneous assault on human

\section{Défendre les pauvres et protéger la nature}

Résumé: «Laudato si'» n'est pas une "encyclique verte», dans un sens réducteur strictement écologique. C'est une louange à la vie et un appel à prendre soin de la maison commune. Dans cet article sont décrits quelques uns des effets négatifs de la dégradation de l'environnement sur les plus pauvres. Ensuite sont décrites les ultimes

' Secretario para la Justicia Social y la Ecología de La Compañía de Jesús, Roma. patxialvarez@ sjloyola.org 
life, the Encyclical devotes extensive attention to this latter issue. In response to this double crisis, the encyclical proposes an integral ecology and develops its content. The paper ends with a conclusion that points to some new paradigms that are mentioned in the letter and that could open up possible ways to solve the socio-environmental crisis we face.

Keywords: integral ecology, socio-environmental crisis, socio-environmental justice, option for the poor, social human development. causes qui produisent cette agression simultanée sur la vie, sujet largement traité dans cette encyclique. La réponse offerte par le documentà cette double crise est une écologie intégrale, tout en développant ses contenus. Le travail finit avec une conclusion qui soulève quelques nouveaux paradigmes, décrits dans la propre LS et qui peuvent ouvrir des voies de résolution à la crise socio-environnementale que nous sommes en train d'affronter.

Mots clés: Écologie intégrale, crise socioenvironnementale, justice socio-environnementale, option pour les pauvres, développement social humain.

Recibido: 15 de diciembre de 2015.

\section{Introducción}

Durante la primera mitad de 2015 se esperaba con ansiedad la publicación de Laudato si', sobre el cuidado de la casa común (LS), como pocas veces antes hubiera sucedido con otras encíclicas. En numerosos círculos-eclesiales, científicos y organizaciones de la sociedad civil- se confiaba en disponer de un texto que demandara con nitidez la protección de la naturaleza y la motivara. Mucho se había trabajado los meses anteriores para que el papa Francisco, que había logrado en solo dos años una elevada autoridad moral más allá de los muros de la comunidad católica, se posicionara en relación a uno de los mayores retos de la humanidad en nuestro tiempo.

Cuando finalmente la encíclica fue dada a conocer al público ${ }^{2}$, se descubrió que el alcance del texto no se limitaba a la protección del medioambiente, sino que situaba este desafío en relación con otras temáticas. Las páginas de LS recuerdan las preocupaciones cardinales que han ocupado a la doctrina social de la lglesia durante más de un siglo, como pueden ser el trabajo digno, el destino universal de los bienes, la opción por los pobres o la defensa de la vida. Asimismo las

2 Firmada el 24-V-2015, solo se hizo pública el 18-VI de ese año. 
reflexiones giran en torno a determinadas cuestiones que regresan a cada rato, enriqueciendo sucesivamente sus contenidos:

la convicción de que en el mundo todo está conectado, la crítica... a las formas de poder que derivan de la tecnología, la invitación a buscar otros modos de entender la economía y el progreso, el valor propio de cada criatura, el sentido humano de la ecología, la necesidad de debates sinceros y honestos, la grave responsabilidad de la política internacional y local, la cultura del descarte y la propuesta de un nuevo estilo de vida (LS 16).

Entre todas estas cuestiones sobresale la íntima relación entre los pobres y la fragilidad del planeta (LS 16).

LS explicita sin descanso esta relación entre los pobres y la vulnerabilidad de la creación: el ambiente humano y el ambiente natural se degradan juntos (LS 48), de tal manera que ambos ambientes se deben afrontar y reflexionar de manera conjunta, considerando que el análisis de los problemas ambientales es inseparable del análisis de los contextos humanos, familiares, laborales, urbanos, y de la relación de cada persona consigo misma (LS 141). Por lo tanto, no hay dos crisis separadas, una ambiental y otra social, sino una sola y compleja crisis socio-ambiental (LS 139). De ahí también que

un verdadero planteo ecológico se convierte siempre en un planteo social, que debe integrar la justicia en las discusiones sobre el ambiente, para escuchar tanto el clamor de la tierra como el clamor de los pobres (LS 49).

En consonancia con esta posición determinante del enfoque, LS propone una "ecología integral"3 que va más allá de un cuidado exclusivo de la creación, abarcando aspectos económicos, sociales, culturales y de vida personal cotidiana desde la perspectiva del bien común.

Por este motivo, no sería adecuado decir que LS es una "encíclica verde", en un sentido reductivamente ecológico. Es una alabanza a la vida y una llamada a cuidar de la casa común: de ahí el título, Laudato si' - alabado seas. LS eleva un canto a la vida, a toda la vida -incluida la humana-, e invita a protegerla allí donde esté amenazada.

En este artículo primero se dilucidarán algunos modos en que la degradación del medioambiente impacta sobre los más pobres. A continuación se mostrarán las últimas causas que producen esta agresión simultánea sobre la vida, una cuestión a la que LS dedica amplia atención. En un tercer apartado se señalará que la respuesta ofrecida por el documento a esta doble crisis consiste en la ecología

${ }^{3}$ A ella dedica todo el capítulo 4, LS 137-162. 
integral, desarrollando sus contenidos. La conclusión apuntará algunos nuevos paradigmas que aparecen esbozados en la propia LS y que pueden abrir vías de solución a la crisis socio-ambiental que afrontamos.

\section{El impacto de la degradación ambiental sobre los pobres}

Desde hace años es conocido que la degradación ambiental está afectando de un modo particular a los más pobres, haciendo aún más difíiil su existencia. El creciente deterioro medioambiental añadirá progresivamente costes adicionales a la vida de los excluidos. El Programa de Naciones Unidas para el Desarrollo (PNUD) dedicó su informe sobre desarrollo humano de 2011 a la doble cuestión de sostenibilidad y equidad ${ }^{4}$. Al reflexionar sobre la relación entre ambas indicaba que

el problema principal son las consecuencias adversas que tiene la falta de sostenibilidad ambiental en el desarrollo humano, en especial para los desfavorecidos de hoy. ${ }^{5}$

Afirmaba también que la degradación del medioambiente afecta más a los pobres y desfavorecidos. Este hecho no sorprende a nadie. ${ }^{6}$

El impacto se produce en una diversidad de formas. LS menciona algunas de ellas. El incremento de contaminantes atmosféricos está afectando a todos los seres humanos, pero especialmente a los más pobres. No pueden trasladar sus viviendas a áreas menos contaminadas $y$, dado que no utilizan combustibles modernos para cocinar ${ }^{7}$, enferman al inhalar niveles de humo elevados y nocivos (LS 20).

Hay empresas que desplazan sus actividades contaminantes hacia los países en desarrollo, actuando en condiciones prohibidas en las naciones de origen (LS 51). El desastre de Bhopal, India, en 1984, donde el accidente de una fábrica de pesticidas de propiedad mayoritaria de Union Carbide -empresa con sede norteamericana- provocó la muerte de millares de personas, permanece como paradigma de la dejación de responsabilidades en actividades desarrolladas fuera

${ }^{4}$ Programa de Naciones Unidas para el Desarrollo - PNUD (2011) Informe sobre Desarrollo humano, Sostenibilidad y equidad: Un mejor futuro para todos; cfr. http://goo.gl/MDJm8L, visita XII-2015.

${ }^{5}$ lbíd., p. 22.

${ }^{6}$ lbíd., p. 49.

7 Ibíd., p. 50. 
del propio país. Es también frecuente la exportación hacia los países en desarrollo de residuos sólidos y líquidos tóxicos (LS 51), donde los impactos sobre la salud de las personas quedan fácilmente ocultos.

Se estima que existen 663 millones de personas que no tienen acceso a agua potable depurada ${ }^{8}$, lo cual es una constante fuente de enfermedades dada la presencia de microorganismos y sustancias químicas. Los niños son los peor parados, elevándose la mortalidad infantil (LS 29). Este problema afecta principalmente a las poblaciones rurales, en las que ocho de cada diez personas aún no disponen de acceso a fuentes de agua potable? ${ }^{9}$. Es también frecuente la contaminación de las cabeceras de los ríos y de los acuíferos por parte de actividades extractivas. Este mundo tiene una grave deuda social con los pobres que no tienen acceso al agua potable, porque eso es negarles el derecho a la vida radicado en su dignidad inalienable (LS 30). Ese mismo número criticará la privatización del agua que limita su acceso a los últimos.

Además de las realidades mencionadas por LS se pueden señalar algunas otras. Enfermedades como la malaria, las paperas, la rubeola, el sarampión y la hepatitis C, así como parásitos como la filariasis y la tenia provocan en conjunto la pérdida de 1,2 millones de vidas cada año ${ }^{10}$. Son personas que pertenecen en su mayoría a comunidades pobres, ya que hablamos de dolencias que pueden ser parcial o totalmente prevenidas o tratadas.

La disminución de reservas ictícolas afecta de modo particular a comunidades que dependen de la pesca para su supervivencia, haciéndolas más vulnerables. Los bancos de pesca están explotados de modo insostenible en numerosas regiones del mundo, impidiendo la reproducción de las poblaciones de peces. Se estima que las especies de agua dulce han disminuido su población en un 75\% entre 1970 y 2010 , lo cual refleja una situación de colapso en numerosos ecosistemas. En el caso de las especies marinas estas se calcula que han descendido en un $40 \%{ }^{11}$.

\footnotetext{
${ }^{8}$ World Health Organization (Organización mundial de la salud - OMS) y UNICEF (2015) Progress on sanitation and drinking water, 2015 update and MDG review; cfr. http://goo.gl/aqfeQH, visita 7-XII-2015.

9 lbíd., p. 9.

10 "Viruses and parasites, eradicating disease": The Economist, 10/16-X-2015, 13.

11 WWF (2014) Living Planet, report 2014, Species and spaces, people and places, en http://d2ouvy59p0dg6k.cloudfront.net/downloads/wwf_lpr2014_low_res_full_report.pdf, visita 22/23-XI-2015.
} 
El cambio climático está multiplicando el número de catástrofes naturales y sus efectos y alterando los patrones climáticos ${ }^{12}$. Los más afectados serán las poblaciones y países pobres, dado que ellos dependen más directamente de recursos eco-sistémicos como la agricultura, la pesca y las actividades forestales.

El cambio climático actual refuerza las condiciones que mantienen a las familias en la pobreza. Los episodios climáticos extremos producen devastaciones en los campos. También generan plagas y enfermedades que dan lugar a gastos añadidos. La pérdida de cosechas eleva los precios de los alimentos. Los pobres son más vulnerables a estos fenómenos porque tienen menor capital inicial y porque sus sistemas de protección familiar, comunitario y financiero son escasos. Es más difícil para ellos prevenir y adaptarse a los efectos del cambio climático. Lamentablemente, existe también el riesgo de que incluso las políticas de reducción de emisiones de gases de efecto invernadero eleven los precios de los alimentos ${ }^{13}$.

El calentamiento global también provocará la elevación de los mares afectando a una buena parte de la humanidad, que vive en zonas costeras. Pero su impacto recaerá nuevamente de modo especial sobre los más pobres (LS 48), que estarán obligados a migrar ante la pérdida de sus viviendas y tal vez también de sus modos de vida.

La migración por motivos climáticos aumenta en el mundo, si bien no se conocen las cifras exactas y las estimaciones de cara al futuro presentan grandes horquillas ${ }^{14}$. En la actualidad no hay reconocimiento de los derechos que puedan amparar a estas personas que se ven obligadas a desplazarse debido a sequías, terremotos o inundaciones. De ahí su situación de desamparo.

Por otro lado, estos impactos que golpean a todos, pero desproporcionadamente a los más desfavorecidos, resultan sumamente injustos, ya que son precisamente las comunidades pobres las que históricamente han contribuido en menor medida al

12 LS señala que los peores impactos recaerán posiblemente en las próximas décadas sobre los países en desarrollo (LS 25).

${ }^{13}$ En noviembre de 2015 el Banco Mundial ha publicado un lúcido y preocupante informe sobre los impactos del cambio climático en la pobreza, sobre el que se basan estos párrafos: WORLD BANK GROUP, 2015, Shock Waves, Managing the impacts of climate change on poverty, en https://goo. gl/VCQixj, visitada en noviembre 2015.

14 Cf. International Organization for Migration, Migration and Climate change, en hitps://goo.gl/ yV8OLN, visita XII-2015. 
cambio climático. También son en la actualidad quienes consumen menor cantidad de recursos naturales: la huella ecológica de los países pobres es notablemente inferior a aquella de los países ricos ${ }^{15}$. Son estos últimos los que se han beneficiado más de los recursos naturales, más han deteriorado el medioambiente y están mejor preparados para protegerse o verse favorecidos por los cambios que, en mayor o menor medida, ocurrirán inevitablemente.

Las poblaciones indígenas merecen mención aparte, dado que en ellas se manifiestan muchas de estas contradicciones tan nocivas para la naturaleza y para los excluidos. La actividad minera en el mundo ha crecido en las últimas décadas, debido al aumento del consumo per cápita y de la población. Esto ha supuesto la expansión geográfica de la minería y de la extracción de recursos naturales. Durante estos últimos años los precios de las materias primas han permanecido elevados, para declinar hace solo unos dos años. En las dos últimas décadas numerosos países en desarrollo han promovido y extendido estas actividades extractivas con el fin de crecer económicamente.

Muchas comunidades indígenas se han visto afectadas por esta expansión de la explotación natural y minera ${ }^{16}$. Han resultado desplazadas de sus tierras, han experimentado la contaminación del suelo y de las aguas y sienten amenazadas sus formas de vida y su cultura (LS 146).

Abundan, por tanto, los procesos de degradación medioambiental que tienen un particular impacto sobre las comunidades más pobres. El deterioro ecológico será una fuente de mayor pobreza y de creciente desigualdad. De ahí que la defensa del pobre deba incluir necesariamente la protección de la naturaleza. La justicia social no está enfrentada a la justicia ecológica, sino que ambas deben reunirse bajo una única justicia socio-ambiental.

\section{Una misma lógica margina y deteriora el medioambiente}

La Encíclica insiste en que una misma lógica está causando la degradación simultánea del ambiente social y ecológico. No hay dos fuentes de causas, sino una sola, que daña la creación y hace este mundo más inhóspito: la misma lógica que

\footnotetext{
15 Puede consultarse una tabla con la huella ecológica por países en WWF, op. cit., 38-39.

16 Puede consultarse Kathrin WESSENDORF (2011) El Mundo Indígena 201 1, en http://goo.gl/o8EVgM, visita 14-XII-2015.
} 
dificulta tomar decisiones drásticas para invertir la tendencia al calentamiento global es la que no permite cumplir con el objetivo de erradicar la pobreza (LS 175). El documento no esclarece de modo sistemático en qué consiste esta dinámica histórica, sino que va aportando en diversos pasajes elementos nuevos, enriqueciendo su contenido.

LS propone una primera componente de esta lógica en el corazón del ser humano. Existen raíces éticas y espirituales (LS 6) profundas que llevan a degradar el entorno. Indicará también que el ser humano postmoderno de hoy corre el riesgo de caer en un individualismo que no mira más allá de sí y de los propios intereses. Este individualismo conduce a un inmediatismo egoísta, a la crisis de lazos familiares y sociales y a las dificultades para el reconocimiento del otro (LS 162). Al ser humano le cuesta hacerse cargo de las dificultades que atraviesan sus congéneres de hoy y de las que tendrán que afrontar los de mañana. Somos nosotros y nuestro particular modo de vida quienes contribuimos a agravar esas dificultades.

En lo hondo de esta primera fuente se encuentra el pecado del ser humano, como origen del abandono de los frágiles y del ataque a la naturaleza, pues rompe las relaciones de armonía con la creación, con el prójimo y con Dios (LS 66).

Una segunda componente a la que alude la Encíclica consiste en el relativismo cultural dominante, que lleva al ser humano a existir bajo la ilusión de que es el creador de sus propios fines. De ahí solo hay un paso a que fácilmente prescinda de los fines que las realidades tienen en sí mismas. Así se ignora el valor intrínseco de las realidades, que son estimadas solo por su valor de uso (LS 6). La voluntad humana se erige en la fuente de significado de la realidad, prescindiendo de verdades previas que puedan guiar la existencia. Cuando nos constituimos en el origen de valor y significado, cambiamos el mundo real por otro virtual a la medida de nuestros deseos. ${ }^{17}$

Si no hay verdades objetivas ni principios sólidos, fuera de la satisfacción de los propios proyectos y de las necesidades inmediatas, ¿qué límites pueden tener la trata de seres humanos, la criminalidad organizada, el narcotráfico, el comercio de diamantes ensangrentados y de pieles de animales en vías de extinción? (LS 123).

Una tercera componente que colorea esta lógica se halla en el actual modelo de desarrollo (LS 43) que -citando a Benedicto XVI-adjetiva de

17 Ésta era la cuestión sobre la que el arzobispo de Canterbury, Rowan Williams, centraba su comentario a LS, en Embracing our limits, IX-2015, en https://goo.gl/wLW5Yt, visita XII-2015. 
superdesarrollo derrochador y consumista, que contrasta de modo inaceptable con situaciones persistentes de miseria deshumanizadora (LS 109). ${ }^{18}$

Ese modo de desarrollo viene espoleado por un consumo inmediatista (LS 162) que ha sido deliberadamente inyectado en nuestra cultura desculpabilizando el ansia de gastar, devaluando la moral del ahorro y depreciando las producciones domésticas a lo largo de todo el s. XX. Esta forma de consumir nada tiene de espontánea. El ser humano actual se siente muchas veces incapaz de resistirse tanto a las tentaciones exteriores, como a los impulsos interiores ${ }^{19}$.

Este modelo de desarrollo se apoya sobre la cultura del descarte, a la que tantas veces alude el papa Francisco, y que afecta tanto a los seres humanos excluidos como a las cosas que rápidamente se convierten en basura (LS 22). No quedan meramente explotados, sino que son superfluos, sobrantes ${ }^{20}$. Con la misma desidia con la que se tira la comida que pertenece a los pobres, se desecha a los excluidos. Una forma de expresión de esta cultura del descarte es la globalización de la indiferencia ${ }^{21}$. Nunca hemos conocido mejor que hoy los problemas que afectan al conjunto de la humanidad, ni ha estado tan a nuestro alcance su solución, pero una enorme masa de personas ignora deliberadamente los sufrimientos de sus semejantes, indiferentes a sus desgracias.

En este mismo contexto LS denuncia el mito del progreso absoluto en un mundo limitado $^{22}$. No puede haber desarrollo real cuando se obvia la premisa de los límites del planeta, que conllevan barreras no franqueables en la utilización de los bienes naturales. Por el contrario, nosotros hemos ignorado los ciclos naturales sobre los que se apoyaban las civilizaciones que nos precedieron, transformándolos en procesos lineales que comienzan con la extracción y que,

\footnotetext{
${ }^{18}$ A ese modelo de desarrollo ("superderrochador y consumista"), Francisco, citando a BENEDICTO XVI (2009) Caritas in veritate, 22, oponía otro que calificaba de "humano integral" (LS 109) y "sostenible e integral" (LS 13), al que nos referiremos más adelante.

${ }^{19}$ G. LIPOVETSKY (2007) La felicidad paradóiica, Ensayo sobre la sociedad de hiperconsumo, Barcelona, Anagrama, 121. Este autor ofrece un agudo análisis de la introducción y desarrollo de las prácticas consumistas en las sociedades.

20 FrancISCO (2013) Exhortación apostólica Evangelii gaudium, 53.

21 lbíd., 54.

22 D. FARES (2015) "Povertà e fragilità del pianeta": La Civiltà Cattolica, n. 3961, 11-VII-2015, 35-49 (aquí, 43).
} 
tras la transformación y el consumo, finalizan en residuos. Estamos llenando el planeta de basura.

Este desarrollo se apoya sobre un paradigma tecnocrático que convierte

la metodología y los objetivos de la tecnociencia en un paradigma de comprensión que condiciona la vida de las personas y el funcionamiento de la sociedad (LS 107).

Lo que prevalecería detrás de este paradigma es una voluntad de dominio, en el sentido más extremo de la palabra ${ }^{23}$.

La razón técnica se sitúa por encima de la realidad. Ese control lo ejercen de modo particular los poderosos, que son los que dominan los debates culturales y el escenario político (LS 52). Todo ello constituye un sistema que ha impuesto la lógica de las ganancias a cualquier costo sin pensar en la exclusión social o la destrucción de la naturaleza ${ }^{24}$.

Como puede apreciarse, desde la perspectiva de LS, existe una única lógica que provoca exclusión y degrada el medioambiente, y que se caracteriza por un modelo de desarrollo espoleado por el consumo, insostenible y excluyente, que utiliza la tecnociencia para imponer su dominio y que se encuentra en manos de los poderosos. Ese modelo es posible en el contexto de un relativismo cultural que priva a las realidades de sus propios fines y erige al ser humano en fuente exclusiva de significados, lo cual degrada las cosas y las valora solo en su utilidad lucrativa. Últimamente esta lógica encuentra su origen en un corazón humano alienado por el pecado.

\section{La propuesta de la ecología integral}

Si la crisis es única, pero con una doble faz, social y medioambiental, también las propuestas de futuro deben incluir, a la vez, ambas dimensiones. Se trata de desarrollar una justicia social y ecológica, que algunos denominan justicia socio-ambiental.

\footnotetext{
${ }^{23}$ En LS 108, citando a Romano Guardini.

${ }^{24}$ Francisco, Discurso en el encuentro con los movimientos populares en Bolivia (9-VII-2015, Santa Cruz de la Sierra), en https://goo.gl/omZE9L, visita XII-2015.
} 
Esta perspectiva choca con otra, también muy extendida y podríamos añadir que dominante, que exige elegir: o bien extendemos el crecimiento económico y el mercado para acabar con la pobreza, admitiendo que esto supondrá necesariamente costes ecológicos añadidos; o bien protegemos la naturaleza y nos olvidamos de los pobres. Esta postura viene a decir que únicamente el progreso material a costa de la naturaleza puede generar los bienes necesarios para acabar con la exclusión. Debemos optar: o inclusión o sostenibilidad, pero no pretender ambos fines. La falacia reside en que, como hemos comprobado, el deterioro medioambiental termina impactando finalmente sobre la vida de los pobres.

Por fortuna, crece en muchos ámbitos la conciencia de que inclusión y sostenibilidad son dos objetivos que perseguir simultáneamente, de tal manera que la lucha contra la pobreza y la defensa del medioambiente deben abordarse de modo conjunto. Y por el contrario, no puede avanzarse en un campo a costa del otro.

Esta convicción está a día de hoy extendida en los organismos internacionales. Por ejemplo, como indica un reciente informe del Grupo del Banco mundial,

para ser social y políticamente aceptables, las políticas de reducción de emisiones deben proteger, e incluso beneficiar, a los hogares pobres. Y para erradicar la pobreza de manera sostenible, las políticas de reducción de la pobreza deben contribuir a la estabilización del cambio climático ${ }^{25}$.

Naciones Unidas acaba de aprobar este año 2015 diecisiete Objetivos de Desarrollo Sostenible, continuación del esfuerzo de los últimos 15 años en torno a los Objetivos de Desarrollo del Milenio. El marco de esta gran empresa consiste precisamente en la persecución simultánea de la erradicación de la pobreza y de la protección del medioambiente. Buscan la prosperidad y el bienestar, al mismo tiempo que intentan preservar nuestro planeta $^{26}$.

Por otra parte, ha habido en las últimas décadas un gran esfuerzo intelectual por superar una interpretación del desarrollo reducida a una mera lectura de la renta. Esta perspectiva critica por equivocada y peligrosa la valoración exclusiva del desarrollo en clave de producto interior bruto ${ }^{27}$. El Programa de Naciones Unidas

${ }^{25}$ Grupo del Banco mundial (World Bank Group) Ondas de choque, Contener los impactos del cambio climático en la pobreza, Nota de política 1/3, XI-2015, en https://goo.gl/TfgToF, visita XII-2015.

${ }^{26}$ Para una presentación somera de los Objetivos del desarrollo sostenible puede consultarse http:// goo.gl/JJA1Vg, visita XII-2015.

${ }^{27}$ Hay abundante literatura sobre el tema; puede consultarse C. TAIBO (2014) $\dot{2}$ Por qué el decrecimiento? Un ensayo sobre la antesala del colapso, Barcelona, Los libros del lince, 29-32. 
para el Desarrollo (PNUD) ha basado sus mediciones del desarrollo humano sobre un conjunto de parámetros que toman en consideración la riqueza, la salud y la educación, añadiendo la variable de la desigualdad para ajustar el resultado final. Desde 1990 sus informes anuales han contribuido a una interpretación más amplia y más adecuada del desarrollo humano.

Estos informes están basados en la línea de pensamiento abierta por Amartya Sen a través de su concepto de desarrollo humano entendido como despliegue de las capacidades humanas. En su misma estela intelectual, Martha Nussbaum ha identificado diez capacidades centrales, entre las que incluye el poder vivir una relación próxima y respetuosa con los animales, las plantas y el mundo natural ${ }^{28}$.

LS sintoniza con estas grandes perspectivas recién mencionadas. Paz, justicia y conservación de la creación son tres temas absolutamente ligados, que no podrán apartarse para ser tratados individualmente so pena de caer nuevamente en el reduccionismo ${ }^{29}$. Señalará también la urgencia de buscar un desarrollo sostenible e integral (LS 12).

Sin embargo, el concepto más utilizado en LS propiamente es el de ecología integral, al que dedica todo un capítulo, el cuarto (LS 137-162). Podríamos decir que este concepto abarca los contenidos de la justicia socio-ambiental -es decir, la inclusión y la sostenibilidad- pero bajo perfiles propios.

La ecología integral comprende una actitud de cuidado de la naturaleza, pero no se limita a ella, sino que incluye un conjunto de ámbitos. Comienza aludiendo a la necesidad de cuidar las riquezas culturales de la humanidad en su sentido más amplio (LS 143), pues las culturas minoritarias se encuentran en riesgo ante el avance de la globalización cultural.

\section{Asimismo demanda prestar atención}

a las comunidades aborígenes con sus tradiciones culturales. No son una simple minoría entre otras, sino que deben convertirse en los principales interlocutores, sobre todo a la hora de avanzar en grandes proyectos que afecten a sus espacios... Cuando permanecen en sus territorios, son precisamente ellos quienes mejor los cuidan (LS 146).

${ }^{28}$ Cf. M. Nussbaum (2012) Crear capacidades. Propuesta para el desarrollo humano, Barcelona, Paidós, donde se recogen las diez capacidades centrales identificadas por la autora.

${ }^{29}$ LS 92, citando a la Conferencia del episcopado de República dominicana. 
Estas comunidades indígenas están amenazadas en todas las latitudes por proyectos extractivistas.

Incluye también una "ecología de la vida cotidiana", asegurando que se produzca una mejora integral en la calidad de vida humana (LS 147). Se trata de disponer de lugares de vida más amables, menos contaminados, más a la medida humana. Incorpora una ecología del propio cuerpo: Aprender a recibir el propio cuerpo, a cuidarlo y a respetar sus significados (LS 155).

Esta ecología integral también está unida a la noción del bien común. El principio del bien común conlleva como consecuencia inmediata una llamada a la solidaridad y a la opción preferencial por los pobres (LS 158).

Como podemos comprobar, el concepto de ecología integral propuesto por LS es un término rico, que abarca la vida en todas sus formas, que tiene una inclinación particular hacia la vida amenazada y que se alinea con términos como desarrollo sostenible e integral o como inclusión y sostenibilidad.

\section{Nuevos paradigmas}

El papa Francisco interpela fuertemente la cultura de hoy: Lo que está ocurriendo nos pone ante la urgencia de avanzar en una valiente revolución cultural (LS 114). Cree que es necesaria una transformación radical. Como decía en Bolivia a los movimientos populares,

queremos un cambio, un cambio real, un cambio de estructuras. Este sistema no se aguanta, no lo aguantan los campesinos, no lo aguantan los trabajadores, no lo aguantan las comunidades, no lo aguantan los pueblos... Y tampoco lo aguanta la Tierra, la hermana madre tierra, como decía san Francisco. ${ }^{30}$

El Papa considera ineludible cuestionar la lógica subyacente en la cultura actual (LS 197). De ahí que hable de una conversión ${ }^{31}$, de un cambio interior, pues el corazón es uno solo, y la misma miseria que lleva a maltratar a un animal no tarda en manifestarse en la relación con las demás personas (LS 92). Se trata de una transformación radical: no podemos pretender sanar nuestra relación con la

\footnotetext{
30 Francisco, 9 julio 2015, Discurso..., cit. En nota 24.

${ }^{31}$ Al que dedica todo un capítulo (LS 216 - 221).
} 
naturaleza y el ambiente sin sanar todas las relaciones básicas del ser humano (LS 119). Tenemos necesidad de nacer de nuevo, no habrá una nueva relación con la naturaleza sin un nuevo ser humano. No hay ecología sin una adecuada antropología (LS 1 18). Propone una mirada distinta, un pensamiento, una política, un programa educativo, un estilo de vida y una espiritualidad nuevas (LS 111).

Esta conversión implica incorporar nuevos estilos de vida, producción y consumo (LS 23). Precisa del cultivo de virtudes sólidas (LS 211), entre las que mencionará la austeridad responsable, la contemplación agradecida del mundo, el cuidado de la fragilidad de los pobres y del ambiente (LS 214). Esa nueva forma de vida encuentra satisfacción en los encuentros fraternos, en el servicio, en el despliegue de los carismas, en la música y el arte, en el contacto con la naturaleza, en la oración (LS 223). Todo esto permitirá desarrollar una mística que nos anime, impulse, motive y aliente (LS 216).

Sin embargo, LS no se limita a orientar hacia una espiritualidad personal y privada. Señala que se precisa una conversión comunitaria (LS 219). Y en distintos lugares va a dar señales de por dónde orientar los cambios.

\section{I. La opción por los pobres}

LS concibe la opción por los pobres como el arco comprehensivo que debe abarcar cualquier escenario deseable. Es una exigencia ética fundamental para la realización efectiva del bien común (LS 158). Esta opción implica una prioridad de las necesidades de los últimos sobre los intereses de los incluidos y particularmente de los poderosos. En realidad es una alteración radical del orden social, que siempre antepone las lógicas de quien detenta la autoridad, para comenzar la obra social desde abajo, asegurando primero que nadie quede atrás, con anterioridad a otras consideraciones.

\subsection{El diálogo}

LS propone el diálogo como el método para hacer frente a la urgente problemática socio-ambiental. Esta es la consecuencia coherente con el hecho fundamental de la interdependencia. Si todo está intrínsecamente relacionado, todos somos corresponsables y debemos afrontar juntos los problemas en su complejidad, sin exclusiones ni omisiones. 
El diálogo tiene la virtud de que en él se produce el reconocimiento del otro, de sus percepciones y razones. Cuando se asiente a ellas, obligan. Por el diálogo alcanzamos una verdad que solo puede ser concebida colectivamente. Sus leyes se habrán de regir por la cordialidad y la simpatía, no solo por la argumentación. Supone un reconocimiento cordial o compasivo del otro. Es ahí donde ya no cabe ninguna exclusión, pues todos tenemos algo valioso que aportar ${ }^{32}$.

El documento eclesial menciona la perentoriedad del diálogo en la política internacional y en políticas nacionales y locales. Señala la necesidad de que los procesos decisionales sean transparentes, expresa la importancia de que la política y la economía dialoguen en búsqueda de la plenitud humana y demanda un diálogo entre religiones y ciencias $^{33}$.

\subsection{El ecologismo de los pobres}

Francisco afirma en LS que para las comunidades aborígenes

la tierra no es un bien económico, sino don de Dios y de los antepasados que descansan en ella, un espacio sagrado con el cual necesitan interactuar para sostener su identidad y sus valores. Cuando permanecen en sus territorios, son precisamente ellos quienes mejor los cuidan (LS ...).

Aparece aquí proyectada la sombra de una realidad, que consiste en que entre los primeros grupos que han defendido la naturaleza se encuentran comunidades pobres -campesinos, pescadores, cazadores, indígenas- a los que les une un lazo primordial con la naturaleza y que dependen de ella para su supervivencia.

Es el ecologismo de los pobres. Ellos se organizan para defender la tierra cuando es amenazada por proyectos de extracción o por la expropiación para otros usos. Sienten las heridas de la tierra como propias y la protegen con mimo. Se saben parte de ella. De hecho, hay hoy un conflicto entre la destrucción de la naturaleza

32 Estas ideas están preciosamente desarrolladas por Adela CORTINA, 2007, Ética de la razón cordial, educar en la ciudadanía en el siglo XXI, Ediciones Nobel, Oviedo.

33 Dedica al diálogo todo el capítulo quinto (163-201), titulado "Algunas líneas de orientación y acción". Por su parte, José Ignacio García desarrolla los principios, criterios y valores a los que, a su entender, apela la Encíclica para desarrollar este diálogo: José Ignacio GARCíA, "El diálogo en Laudato

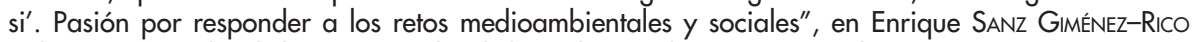
(ed.), 2015, Cuidar de la Tierra, cuidar de los pobres, Sal Terrae, Santander, pp. 125-140, 132-135. 
para el lucro y su conservación para poder sobrevivir. Este ecologismo se está configurando en una fuerza en favor de la sostenibilidad ${ }^{34}$.

\subsection{El decrecimiento}

En LS se menciona un concepto atrevido, el decrecimiento:

Es insostenible el comportamiento de aquellos que consumen y destruyen más y más, mientras otros todavía no pueden vivir de acuerdo con su dignidad humana. Por eso ha llegado la hora de aceptar cierto decrecimiento ${ }^{35}$ en algunas partes del mundo aportando recursos para que se pueda crecer sanamente en otras partes (LS 193).

Nuestra economía no es post-material, al contrario, su producción requiere recursos materiales crecientes. En realidad, en el mundo se ha incrementado la demanda de minerales a mayor velocidad que el producto interior bruto ${ }^{36}$. Esto, en un planeta limitado y el nuestro lo es, supone la insostenibilidad de todo un modo de vida, al que paradójicamente parece que todos debamos aspirar.

Los países pobres necesitan seguir creciendo económicamente para responder a las necesidades básicas de su población desasistida y vulnerable. En realidad, lo que queda cuestionado es si el objetivo del crecimiento económico es aún un objetivo legítimo en los países ricos ${ }^{37}$. Esta afirmación resulta profundamente inquietante, pues la economía dominante solo tiene mecanismos de redistribución en condiciones de crecimiento económico. La recesión multiplica la exclusión y la desigualdad. Esto nos indica que necesitamos un nuevo paradigma económico que distribuya riqueza en condiciones de decrecimiento.

En realidad, en los países ricos hay para todos. En ellos podemos alcanzar una prosperidad sin crecimiento, para que los países pobres puedan tener una pros-

${ }^{34}$ Cf. J. Martínez Alier ( ${ }^{5} 2011$ ) El ecologismo de los pobres. Conflictos ambientales y lenguajes de valoración, Barcelona, Icaria.

${ }^{35}$ En cursiva el original.

${ }^{36}$ T. JACKSON (2011) Earthscan, Prosperity without growth, Economics for a finite planet, LondresWashington, 75.

37 lbíd., 17. 
peridad con crecimiento ${ }^{38}$. Lo que algunos proponen es que segmentos enteros de la economía que están en la base de la insostenibilidad, como la industria del automóvil, la construcción, la aviación, la militar... reduzcan su actividad, mientras se propicien actividades económicas en la atención de necesidades sociales ${ }^{39}$. El decrecimiento puede liberarnos de la voluntad de explotar la naturaleza, permitiéndonos desplegar capacidades genuinamente humanas. Más inclinados así a la contemplación y menos al dominio ${ }^{40}$. Nos adentramos en tierra desconocida.

\subsection{La civilización de la pobreza}

Ésta es una expresión que se remonta a lgnacio Ellacuría ${ }^{41}$, que consideraba que las lógicas dinámicas de los pobres, es decir, su solidaridad, su creatividad, su deseo de incluir a todos, su sobriedad, su capacidad de fiesta y esperanza, eran radicalmente necesarias para la transformación requerida por el mundo. Por el contrario, la civilización de la riqueza nos aboca a su perdición.

La palabra civilización apunta a un cambio radical, en la misma línea que el papa Francisco. En realidad este les decía a los movimientos populares:

ustedes, los más humildes, los explotados, los pobres y excluidos, pueden y hacen mucho. Me atrevo a decirles que el futuro de la humanidad está, en gran medida, en sus manos, en su capacidad de organizarse y promover alternativas creativas... Ustedes son sembradores de cambio ${ }^{42}$.

Estas expresiones beben de la misma fuente evangélica que señala a un niño nacido en un pesebre como salvador del mundo. No son meras afirmaciones teóricas, sino que deben de estar respaldadas por la fuerza de alguna vivencia personal.

\footnotetext{
${ }^{38}$ L. Boff (2013) La sostenibilidad, qué es y qué no es, Santander, Sal Terrae, 67.

${ }^{39}$ C. TAIBO, op. cit., 75.
}

40 Cf. S. Latouche (2011) La sociedad de la abundancia frugal. Contrasentidos y controversias del decrecimiento, Barcelona, Icaria, 43. Este autor es un referente del estudio del decrecimiento en su versión radical.

${ }^{41}$ Cf. I. Ellacuría, "Utopía y profecía desde América Latina. Un ensayo concreto de soteriología histórica", en J. A. SENENT, editor (2012) La lucha por la justicia. Selección de textos de Ignacio Ellacuría (1969-1989), Bilbao, Universidad de Deusto, 401-449.

42 Francisco, 9 julio 2015, Discurso..., cit. en n ${ }^{a} 24$. 
Tratando de salvaguardar parte del significado de esa "civilización de la pobre$\mathrm{za}^{\prime \prime}$, pero intentando evitar las enemistades que genera un lenguaje provocativo, algunos autores han desarrollado otras expresiones como sobriedad solidaria"43, señalando así la necesidad de cultivar una sencillez de vida en solidaridad generosa con los últimos.

La conversión necesaria se hace muy cuesta arriba, parece sencillamente imposible. Y sin embargo hay esperanza:

Junto con todas las criaturas, caminamos por esta tierra buscando a Dios... Caminemos cantando. Que nuestras luchas y nuestra preocupación por este planeta no nos quiten el gozo de la esperanza (LS 244).

Como dijo papa Francisco en Bolivia en el Segundo encuentro con los movimientos populares celebrado en Santa Cruz de la Sierra en 2015:

De esas semillas de esperanza sembradas pacientemente en las periferias olvidadas del planeta, de esos brotes de ternura que lucha por subsistir en la oscuridad de la exclusión, crecerán árboles grandes, surgirán bosques tupidos de esperanza para oxigenar este mundo ${ }^{44}$.

En definitiva, LS muestra los modos en que se deterioran conjuntamente el medioambiente y el entorno humano, reflexiona sobre las causas que generan ese daño, propone la ecología integral como horizonte de soluciones deseables y sugiere algunos posibles paradigmas de futuro para mejor defender al pobre y proteger la naturaleza simultáneamente.

43 J. M. CaAmaño, "La encíclica Laudato si" y la teología moral", en E. SANZ GImÉnez-RIco S.I., editor (2015), op. cit., 141-168 (aquí 164).

${ }^{44}$ Francisco (2015) Discurso... cit. en nota 24. 